\title{
Development of an IoT-based Students' Attendance Monitoring System
}

\author{
Ezeofor Chukwunazo Joseph \\ Department of Electrcal/Electronic Engineering \\ University of Port Harcourt, Rivers State, Nigeria
}

\author{
Georgewill Onengiye Moses \\ Rector, Ken Saro Wiwa Polytechnic Rivers State, \\ Nigeria
}

\begin{abstract}
This report presents development of an IoT-Based student attendance monitoring system using University of Port Harcourt as a case study. In the University of Port Harcourt, attainment of $75 \%$ attendance of every student is one of the criteria for a student to be qualified to sit for any course in any of the semester's examination. The system is aimed to effectively monitor the $75 \%$ attendance of every student. The system composed of hardware and web application. The hardware consists of; Power supply, fingerprint biometric sensor, Esp 32 controller, Thin film transistor (TFT) Liquid Crystal display and Light emitting diode (LED) while the software consists of; Webpage, Embedded $\mathrm{C}$ language and My structured query language (MySQL) Database. The fingerprint sensor registers the students during the course registration exercise and authenticates students during attendance in class. The Esp 32 microcontroller with $\mathrm{WiFi}$ enabled connects the system to the webpage for data storage and displays information via TFT LCD. MySQL is used for online database for students' attendance storage system. The course lecturers are allowed to gain access only to their class attendance register platform while the Head of department would have access to all the attendance registers online. The system was designed and tested by registering students and taking attendance with optimum performance.
\end{abstract}

Keywords-IoT; MySQL Database; TFT LCD; Finger print sensor; Javas; Esp 32 Controller, PHP; HTML

\section{INTRODUCTION}

The performance of a student undergoing any form of learning in academic institution in Nigeria depends on a number of factors. The attendance of the students to classes is one of the factors as pointed out by Luca (2010). His study showed that attendance is statistically significant and quantitatively relevant in students learning. Daniel (2010) revealed that students who missed classes in a given date were significantly more likely to respond incorrectly to questions relating to materials covered that day than students who were present. Every academic institution in the world now poses some form of standard requirement, for students in their respective institutions to participate in their examination.

In the University of Port Harcourt Nigeria, attainment of $75 \%$ attendance by every student is one of the criteria for a student to be qualified to take any semester's examination in any course. One of such system is the manual attendance process; the lecturer either gives a sheet of paper to the students to write their names and append their signatures as a form of confirming their presence for a particular class lesson or calls the attendance register himself/herself. This makes falsification of attendance very easy especially in large classes where count can take a long time. In developed nations, attendance has moved from the manual systems to an electronic system. This has call for an accurate record of the data of students as regards to their performance in attending lectures.

\section{LITERATURE REVIEW}

With the present advances in technology such as; recognition systems, control systems, design of smart devices, IOT and other projects, tremendous research work has been carried out lately to eradicate the problems associated with the old, cumbersome and less efficient ways of monitoring attendance to a more efficient, automated, less cumbersome and digital systems. In attempt to replace older systems with more efficient ones, various attendance systems have been deployed. Abubakar et al (2018) used a fingerprint module (sensor), wireless communication network (WIFI), visual basic and MySQL (database) to convert the wired fingerprint recognition system to a wireless finger print recognition through the Wi-Fi network to the user's computer only where the database is situated. The limitation of this design is that the range of the communication is about $500 \mathrm{~m}$ and the information is only available in one system. Ms. Jagruti et al (2018) presented a simple and portable approach to student attendance in the form of an IoT based system that uses fingerprint scanner and stores the data securely over the cloud and data can be retrieved whenever the teacher wants it.

\section{SYSTEM DESIGN METHODOLOGY}

The design approach adopted is top-down which comprises of hardware and software sections as shown in fig. 1a and fig. $1 b$.

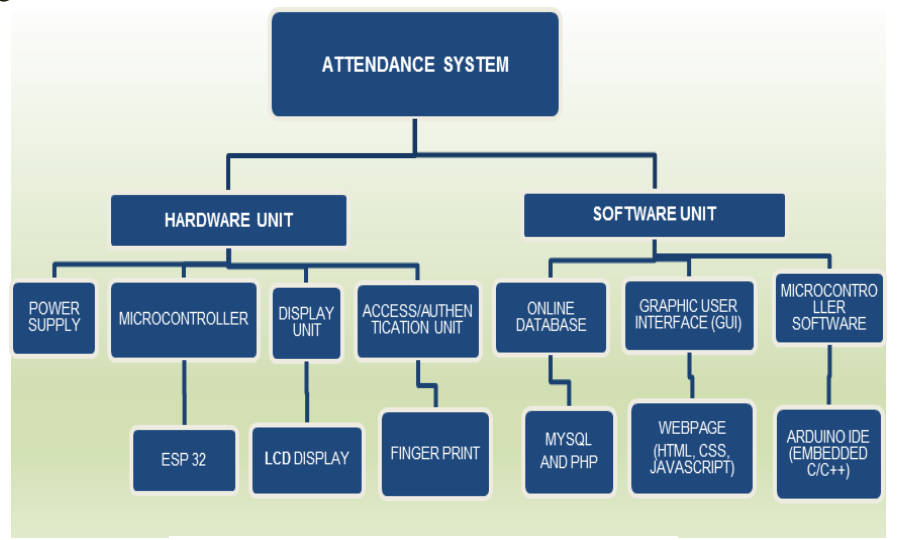

Fig.1a: Architecture of Student Attendance

System 


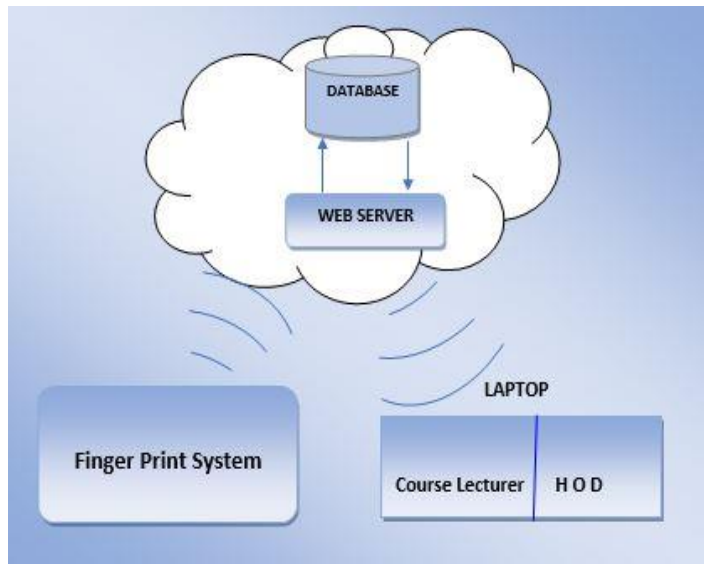

Fig.1.1b: System block diagram

\section{A. Harware section of the System}

The hardware unit of the system composed of power supply, microcontroller-Esp 32, Thin Film Transistor (TFT) Liquid crystal displays (LCD), and finger print sensor. Each of the units is described as follows:

1) Power supply: The system requires $+5 \mathrm{DC}$ voltage for its optimium performance. The $+5 \mathrm{DC}$ voltage is captured by connecting (step-down transformer, bridge diodes, capacitor, regulator) together.

2) Esp 32 Microcontroller (fig.2): is an IoT microcontroller with a single $2.4 \mathrm{GHz}$ WI-Fi-and-Bluetooth combo chip designed with ultra-low-power $40 \mathrm{~nm}$ technologies. It can also be used for electronic wearable.

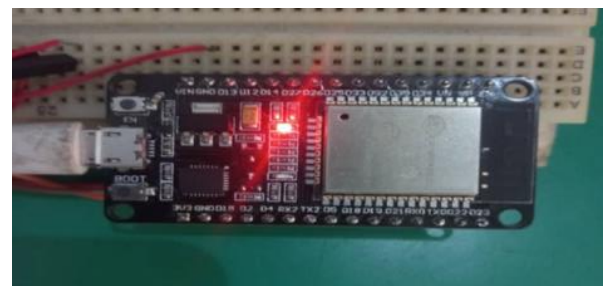

Fig. 2: Esp 32 Microcontroller of the system

3) Thin Film Transistor (TFT) LCD: is a variant of LCD display that uses thin film transistor technology instead of light modulating properties of crystals to display images. It is used in appliances such as television and mobile phones etc. which do not emit light directly, instead using a backlight or reflector. TFF LCD was developed by Paul K. Weimer using MOSFET technology and comes in different sizes and colours as shown in fig. 3 .

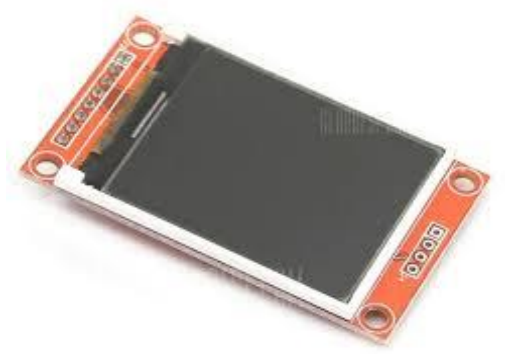

Fig. 3: TFT LCD
4) Finger Print Sensor: The commonest form of biometric identification is the use of fingerprint sensor shown in fig. 4. This particular fingerprint sensor is emplyed because it is easy to use and also comes with fairly straightforward Arduino library to enable its functionality and easy testing.

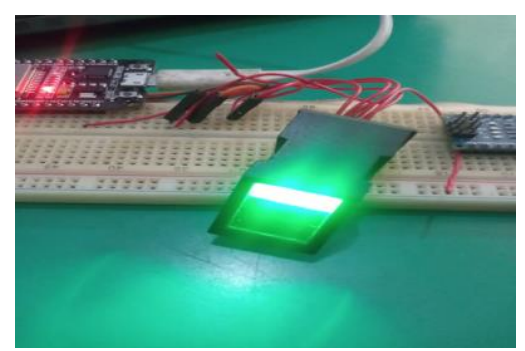

Fig. 4: Finger print sensor

The system hardware components are connected as shown in

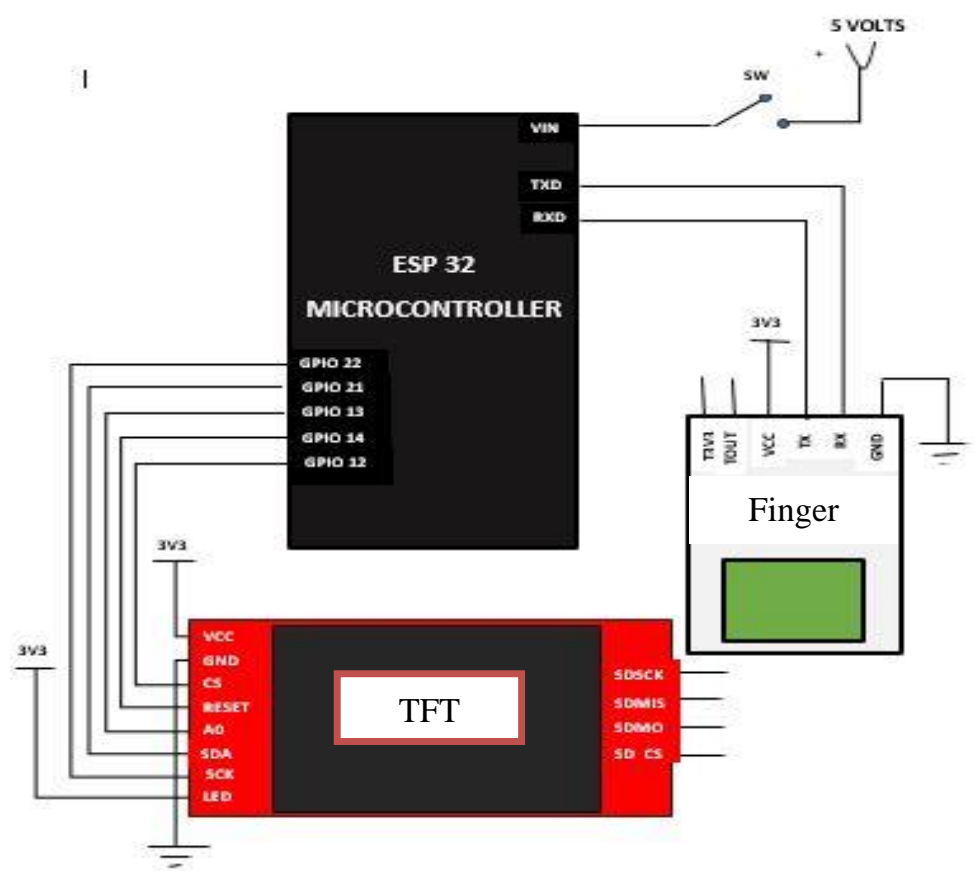

Fig. 5: System circuit diagram

\section{B. Software section of the System}

Two major computer languages were used to develop the programs that control the microcontroller and online web portals.

1) Embedded $C$ language: was used to program Esp 32 microcontroller to allow all the hardware components to work efficiently.

2) Web portals development: this is the interface where users interact with the system to either get data from the system or store data in the system. The webpages for the student's attendance management system are designed using HTML (for the structure), CSS (to style the web pages), and JavaScript (to add functionality of the webpage).

3) Online DataBase: MySQL is an open source relational database management system (RDBMS) for storing student attendance record in the cloud. PHP is also a general- 
purposed programming language originally designed for web development used to receive data from the client side, manipulate data to be stored and transfer the data to MySQL database for storage.

\section{System Algorithm and Flow Chart}

Different algorithms and flow charts were generated. The algorithm for students and lecturers' online registration process is shown below.

1) Stuudents Finger Print Registration: The algorithm for fingerprint registration process for both the lecturers and the students are written below

- Start.

- Initialize the system.

- Is a human finger on the sensor interface?

- Yes: Scan the finger.

- No: Go to step 3.

- Is scan is ok?

- No: Go to step 3.

- Yes: Is D4 = 1?

- Yes: The system Creates Model.

- The system stores the fingerprint model created.

- No: the system search database for a match.

- Is match found?

- Yes: send to database online.

- No: Go To step 8

The flow chart for students and lecturer's registration process is shown in fig. 6 .

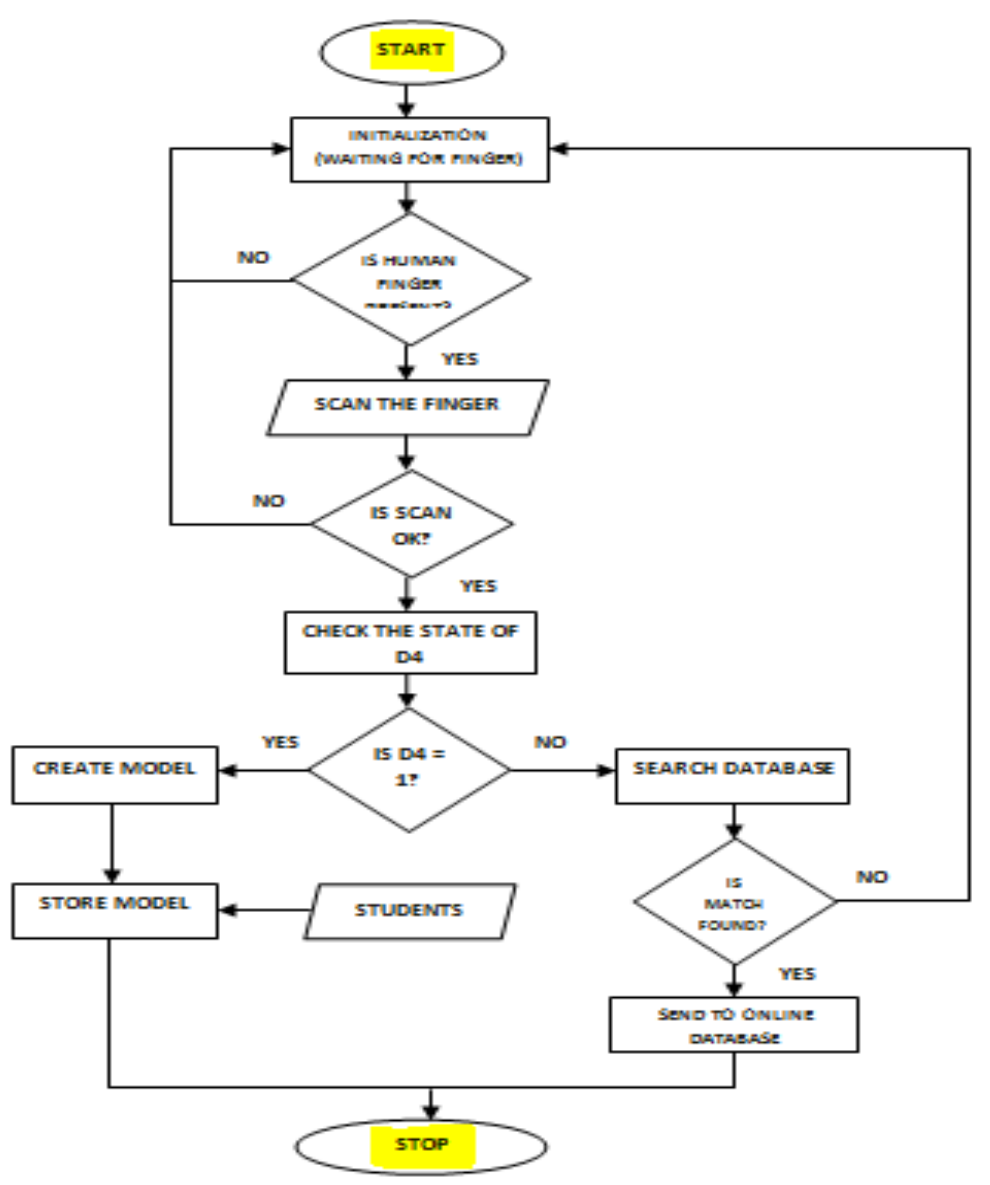

2) Online and Database System: The algorithm for online and database is shown below

- Start

- Login to website

- Is lecturer registered? No, click lecturer register;

- Yes, store data to database;

- $\quad$ Else if not registered, return to step 3.

- If student and not registered, click students register.

- If registered, save data to database;

- $\quad$ Else if not registered, return to step 6.

- Else if, lecturer and registered, click login;

- Input login details and click login button.

- View attendance for any course of interest

- $\quad$ End

The flow chart for online and database system is shown in fig. 7 .

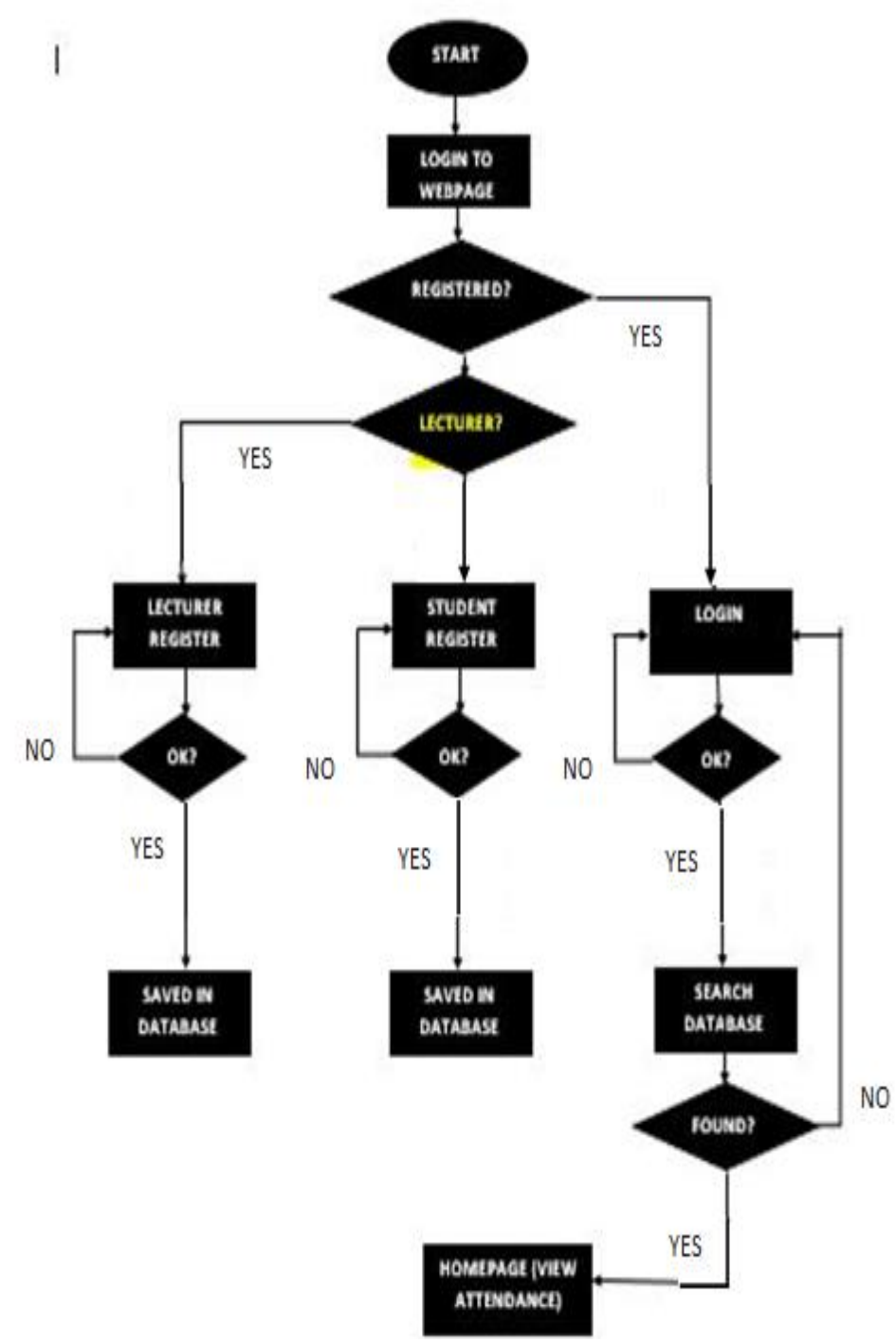

Fig. 7: Flow chart for online and database system

Fig. 6: Flow chart for students and lecturer's registration process 


\section{RESULT \& DISCUSSION}

Various tests were conducted in Arduino IDE to ensure that the system hardware and software are working perfectly.

1) Hardware Test: Different hardware components were tested during the system implementation stages.

- Microcontroller Esp 32 Test: Flash memory (fig. 8) was checked by uploading a program. The WiFi was also checked by uploading connectivity program using router's network credentials.

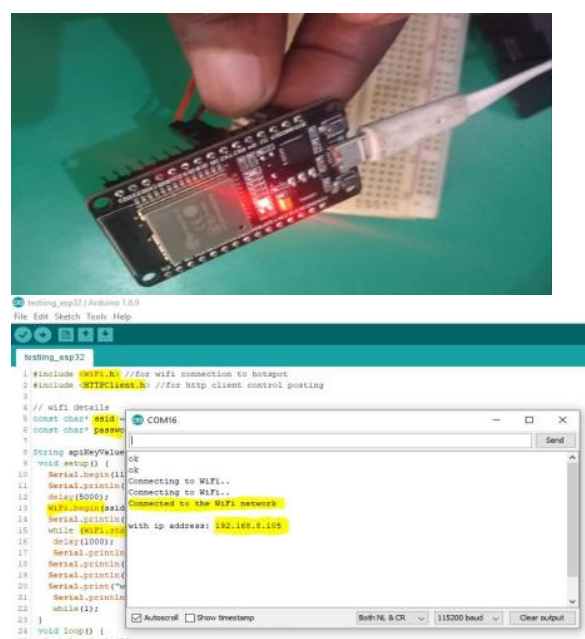

Fig. 8: Esp 32 Microcontroller flash memory test

- Finger Print Sensor Test: datasheet of the fingerprint sensor was used to check its pin configuration, power requirements and connection established using UART cable. The Finger Print Manager (FPM) library downloaded from github and scan print program uploaded and tested as shown in fig.9.

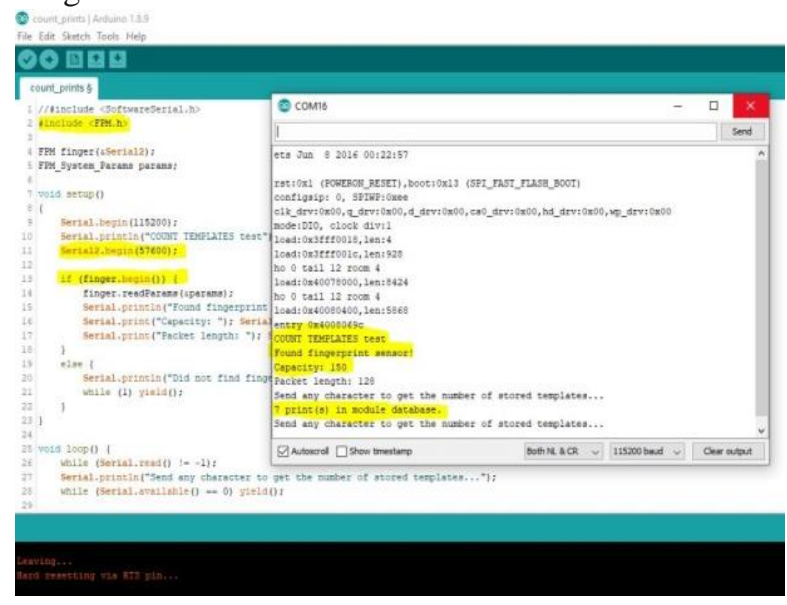

Fig.9: Finger print program test

- TFT LCD Test: the pin configuration of the TFT LCD was confirmed using datasheet. TFT.h library was downloaded from Github and loaded in the Arduino IDE. The module was interfaced with the microcontroller and a sketch was uploaded to the ESP 32 microcontroller. After the upload, message from the sketch was printed in the TFT module successfully as shown in fig. 10 .

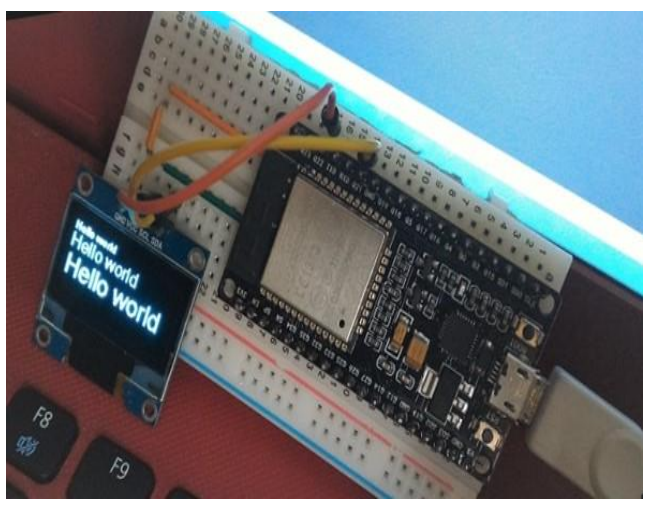

Fig.10: TFT LCD test

2) Esp 32 Microcontroller program Test: the codes that controls the entire system was written using embedded $\mathrm{C}$ language. The Arduino IDE is a program development environment where the embedded $\mathrm{C}$ program for finger print capture was written. The written codes are shown here

Start:

Print ("Students biometric Registration");

While (finger $==$ no finger) $\{\quad$ // while finger is not placed on the sensor

Print ("Please place valid finger"); // Print message

If (finger $==$ finger present) \{ // if now placed on the sensor

Finger1 = read (valid finger); // capture fingerprint

\}

While (finger $==$ no finger) \{ // while the finger is not placed on the sensor

Print ("place valid finger again"); //print message

If (finger $==$ finger present) \{

// if now placed on the sensor

Finger2 = read (valid finger); // capture fingerprint

$$
\begin{gathered}
\text { \} }\} \\
\text { If (Finger1 == Finger2) }\{\quad \text { //compare } \\
\text { fingerprints for features } \\
\text { Store (Finger1, 1); } \\
\text { print in the print database with ID }=1
\end{gathered}
$$

End:

Where: $/ /=$ comment

3) Software Test: various program codes written using different computer languages were tested during the system implementation stages as detailed below:

- Web Pages Test: Notepad++ was used to test HTML, PHP and JAVASCRIPT written codes for online web pages. The htdocs folder stores all the 
files and programs for the web pages. The login platform (fig.11a) is used by the lecturer and Head of Department (HOD) to register and check students that attended lecture in any course.

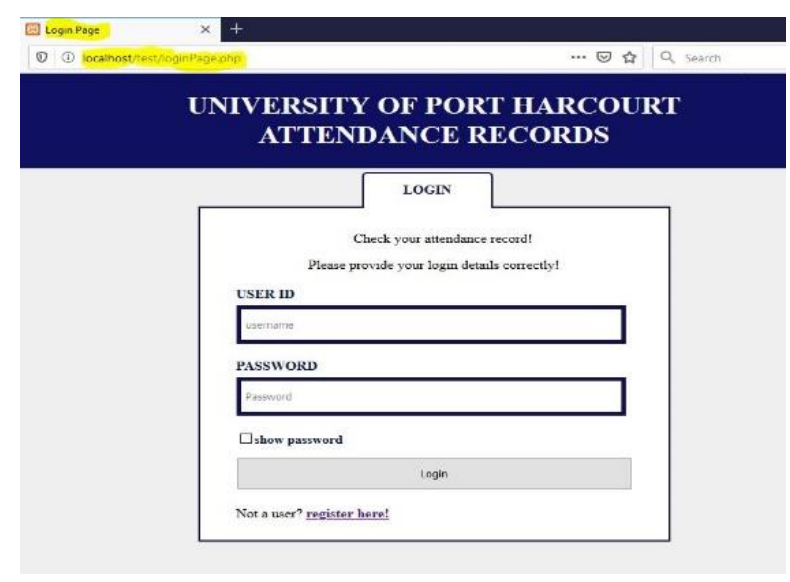

Fig.11a: Login platform

Student's registration platform (fig.11b) is used to register students into the system for storage and can be accessed by the lecturers and HOD remotely.

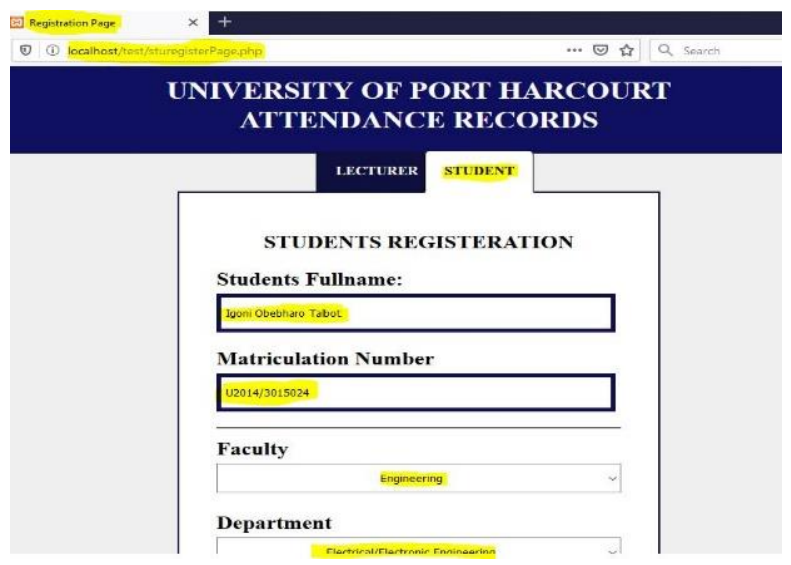

Fig.11b: Student's Registration Platform platform

Attendance record platform (fig.11c) is used by the course lecturer to view the registered students in his/her courses and also those students that attended his/her classes.

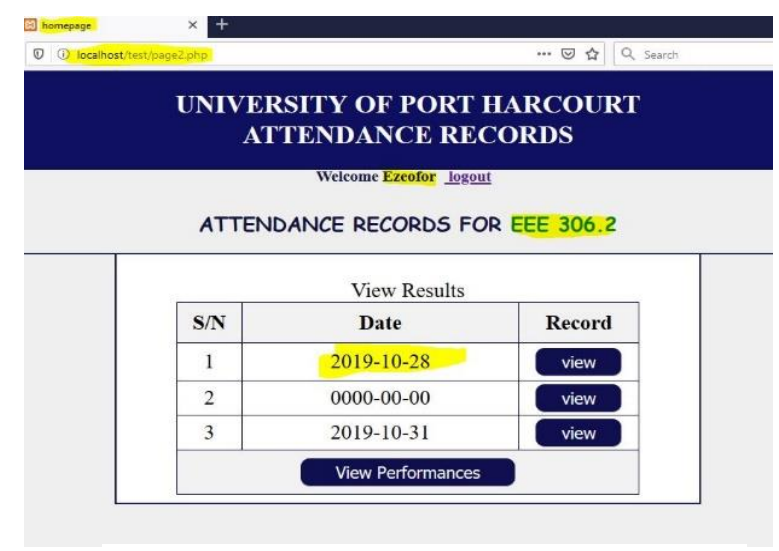

Fig.11c: Attendance record platform
Percentage performance platform (fig.11d) is used by the course lecturers to check and view the percentage of students that qualify to take exam in any semester. University of Port Harcourt uses $75 \%$ attendance to permit students to write semester's examination.

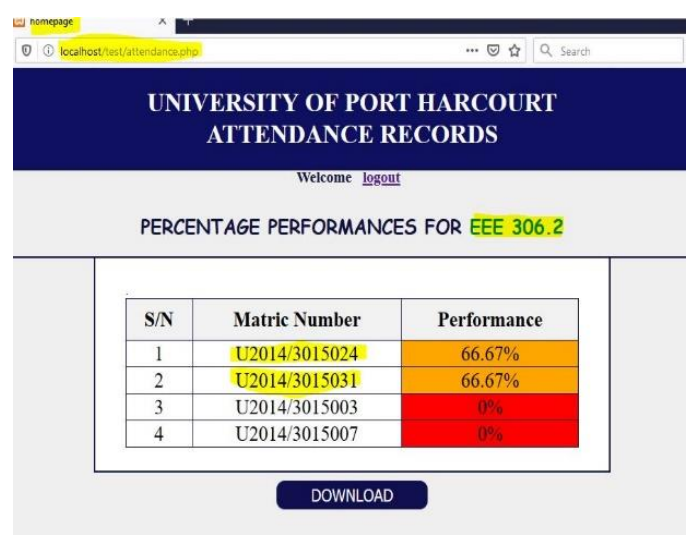

Fig.11d: Percentage performance platform

- Database Test: database and tables were created and tested by inputting students' matriculation numbers into the database and view using phpMyAdmin (fig.12). After testing, the database was linked with the webpages created to create the finished websites.

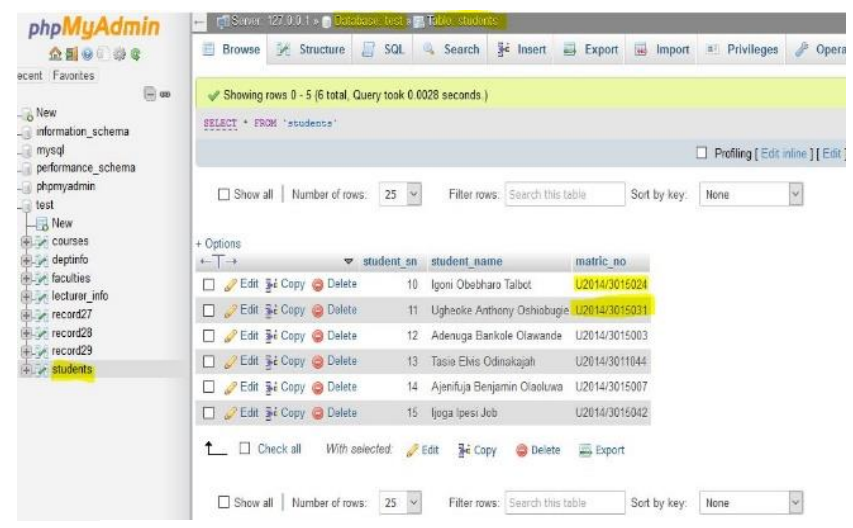

Fig.12: Database test using phpMyAdmin

4) System Packaging: After interfacing the Fingerprint, TFT LCD and switch to the ESP 32 microcontroller on the Strip board, the circuit is enclosed inside the PVC joint box used for the packaging. The interior view of the hardware is as shown in fig.13a and the exterior view of the system is shown in fig. $13 \mathrm{~b}$.

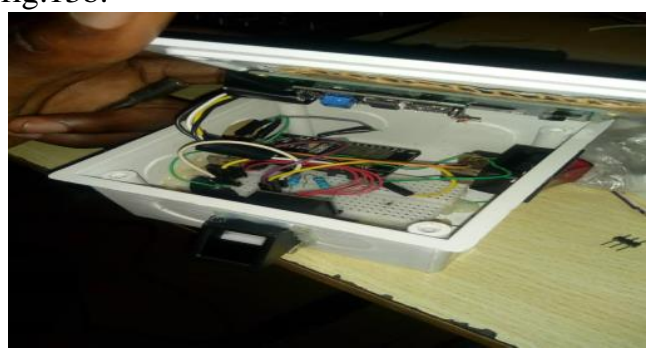

Fig.13a: Interior view of the Finger print system Finger system 


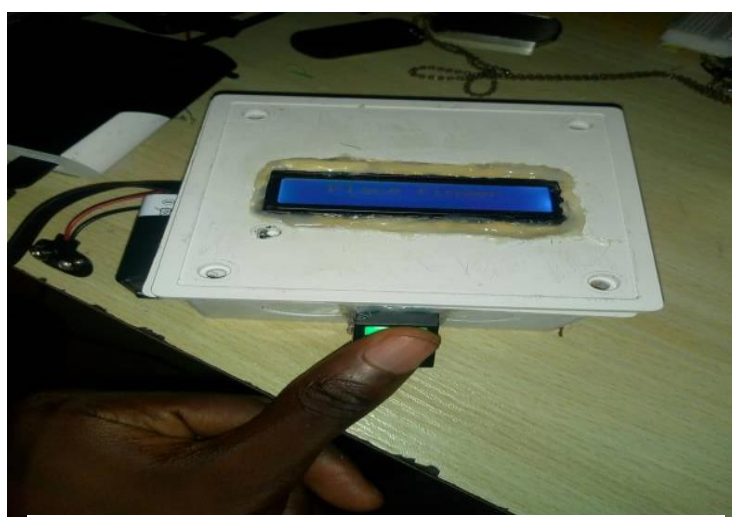

Fig.13b: Exterior view of the Finger print system Finger system

\section{CONCLUSION}

The IoT based student attendance monitoring system provides a reliable data management and storage system for monitoring the attendance performance of students. This system can also help shape student's attitude to learning. Since the aim of the University educational system is to train and educate students in character and learning, this work would help University checkmate students during learning period. Using Optical fingerprint and Esp 32 IoT microcontroller, the student's attendance is recorded and sent to the online database which can be retrieved by the lecturers and HODs when the need arises. The system is designed to assists the University to promote excellence and make decisions pertaining student's performance in attending classes and siting for examination. This system adopts Wi-Fi communication technology and protocol that enables it communicates with smart devices such as android smartphones, personal computers etc. It also aimed at providing help to the goal of the institution by monitoring and keeping proper records of the attendance of the students, store data online and ease in calculating the percentage attendance of student to ascertain if a student met the standard requirement before entering examination hall. This would aid University of Port Harcourt to trace students that are qualified to sit for any examination and sanction those not qualified.

\section{REFERENCES}

[1] A. I. Abubakar, P. K. Kpochi and J.S. Eiyike, "Design and implementation of a smart attendance register", International Journa of Advance Engineering and Research Development, Vol. 5 issue 2. 2018.

[2] F. Akter, A.B. Akhi, N.J. Farin, Md.M. Khondoker and Md.G. Saklayen, "IoTSAMS: a novel framework for Internet of Things (IoT) Based Smart Attendance Management System", Intelligent Contro and Automation, Vol. 9, 2018, pp.74-84. DOI /10.4236/Ica.2018.93006

[3] R. Hasaneind, S. A. Nabeel, F. Ali Al, A. Basheer and A. Haider, "Attendance and information system using RFID and web-based application for academic sector", International Journal of Advanced Computer Science and Applications, Vol. 9, issue 1, 2018.

[4] J. Sonalisatyarupa and M. Akankshya, "IoT based distributed attendance system", International Journal of Scientific \& Engineering Research Vol. 9, issue 4, 2018, http://www.ijser.org.

[5] M. Olagunju, A. E. Adeniyi and T. O. Oladele " "Staff attendance monitoring system using fingerprint biometrics", International Journal Of Computer Applications, Vol. 179, issue 21, 2018.

[6] K. K. Md. Abdul, A. S. Towqir, Z. K. Abdullah, R. Mahbubur and S. A. Mohammad, "A paper titled: a portable and less time consuming wireless biometric attendance system for academic purpose using Nodemcu microcontroller", 21st International Conference of Computer and Information Technology (ICCIT), pp. 21-23, 2018.

[7] P. Anilkumar, M. Akash, S. Sonica, "Iot Based Attendance System", International Research Journal of Engineering and Technology (IRJET), Vol. 4, issue 2, 2017, www.Irjet.net.

[8] H. K. Arfinsayyed, K. Khubalb, A. Shumala, "Fingerprint based attendance system using IoT", International Journal of Advanced Computer Science and Applications, Vol. 9, issue 1, 2017.

[9] K. Devendra, S. S. Yadav, P. Shashank and M. Pragyan, "Fingerprin based attendance system using microcontroller and LABVIEW", International Journal of Advanced Research in Electrical, Electronics and Instrumentation Engineering. Vol. 4, issue 6, 2015.

[10] J. R. Ms. Jagruti, A. Ms. Snehal, K. P. Rahul and R. G. Ms. Ashwini, "IoT Based Biometric Attendance System", Journal of Science and Engineering, Vol. 2, Issue 4, 2018

[11] S. Luca, "The effect of attendance on academic performance. Pane data evidence for introducing micro economics", Journal of Economic Education, 2010

[12] R. M. Daniel, "Research in economic education: absenteeism and undergraduate exam performance", Journal of Economic Education, Vol. 32, issue 2, 2010 . 